\title{
Myeloperoxidase G-463A polymorphism and risk of lung and prostate cancer in a Turkish population
}

\author{
SERDAL ARSLAN $^{1}$, HATICE PINARBASI ${ }^{2}$ and YAVUZ SILIG ${ }^{2}$ \\ ${ }^{1}$ Department of Molecular Biology and Genetics, Faculty of Science, and ${ }^{2}$ Department of Biochemistry, \\ Faculty of Medicine, Cumhuriyet University, 58140 Sivas, Turkey
}

Received July 22, 2010; Accepted September 29, 2010

DOI: $10.3892 / \mathrm{mmr} .2010 .378$

\begin{abstract}
Myeloperoxidase (MPO) is a phase I enzyme that can bioactivate many specific procarcinogens, including polycyclic aromatic hydrocarbons and aromatic amines. The MPO gene contains a common single nucleotide polymorphism, for which the $-463 \mathrm{G}>\mathrm{A}$ substitution within the promoter region has been shown to reduce MPO expression and activity. We investigated the association between the $M P O-463 \mathrm{G}>\mathrm{A}$ polymorphism and lung and prostate cancer in a Turkish population. MPO genotypes in the study populations were determined using polymerase chain reaction-based restriction fragment length polymorphism assay. The allelic frequency was significantly different between the cases and controls for lung cancer $(\mathrm{p}=0.02)$, but not prostate cancer $(\mathrm{p}=0.30)$. No significant difference was noted between the lung and prostate cancer cases and control populations in terms of genotype distribution ( $\mathrm{p}=0.07, \mathrm{p}=0.53$, respectively). Control groups of lung and prostate cancer were in Hardy-Weinberg equilibrium ( $\mathrm{p}=0.87$ and $\mathrm{p}=0.41$, respectively). To determine the protective effect against lung cancer among individuals with the $-463 \mathrm{~A}$ allele, G/A and A/A genotypes were combined. Comparison of the $\mathrm{G} / \mathrm{G}$ and $\mathrm{G} / \mathrm{A}+\mathrm{A} / \mathrm{A}$ genotypes between the lung cancer cases and control groups showed a statistically significant relationship $(\mathrm{p}=0.032, \mathrm{OR}=0.60,95 \%$ CI $0.38-0.95)$. No gender-specific difference was found in terms of genotype distribution between the lung cancer patients and the controls (female, $\mathrm{p}=0.20$; male, $\mathrm{p}=0.34$ ). In the case of smokers, a difference in genotype distribution between the lung cancer patients and the controls was statistically significant $(\mathrm{p}=0.02)$, although this difference was not statistically significant for non-smokers $(\mathrm{p}=0.90)$. Overall, no statistically significant difference was found between the prostate cancer cases and the controls in terms of genotype combination $(\mathrm{p}=0.46$, $\mathrm{OR}=0.83,95 \% \mathrm{CI}$ 0.51-1.36). Additionally, in smokers and
\end{abstract}

Correspondence to: Dr Yavuz Silig, Department of Biochemistry, Faculty of Medicine, Cumhuriyet University, 58140 Sivas, Turkey E-mail: ysilig@cumhuriyet.edu.tr

Key words: lung cancer, prostate cancer, myeloperoxidase, polymorphism, Turkish population non-smokers, no significant relationship was determined between the prostate cancer patients and the control population $(\mathrm{p}=0.21, \mathrm{p}=0.91$, respectively). These results suggest that the $M P O-463 \mathrm{~A}$ allele significantly contributes to a protective effect overall and in smokers against lung cancer.

\section{Introduction}

Myeloperoxidase (MPO) is an oxidative lysosomal enzyme that is available in polymorphonuclear neutrophils and monocytes. MPO is a phase I enzyme that can bioactivate many specific procarcinogens, including polycyclic aromatic hydrocarbons and aromatic amines (1). The MPO gene is located on chromosome 17q23.1 and consists of 11 introns and 12 exons. The MPO gene contains a common, single nucleotide polymorphism (rs2333227) within the MPO -463 gene promoter. As a result of the G-463A polymorphism on the 5' untranslated region of the $M P O$ gene, the SP1 binding site of Alu hormone components disappears and the $-463 \mathrm{~A}$ allele exhibits a 25 -fold decreased MPO expression in vitro (1-3). Individuals with the $-463 \mathrm{~A}$ allele may be afforded protection due to the decreased transcriptional activity of MPO and subsequent decreased metabolic activation of procarcinogens.

Lung and prostate cancer are among the most common forms of cancer and are the cause of most cancer-related deaths worldwide (4). In the US, lung cancer accounts for approximately $15 \%$ of all cancer cases and $29 \%$ of all cancer-related deaths. Prostate cancer alone accounts for approximately $25 \%$ of all cancer cases and $10 \%$ of all cancer-related deaths in men (4). Some reports suggest that the risk of developing cancer is modified by both genetic and environmental factors, such as diet, hormone levels, drinking habits, ethnicity and genetic background (5). To the best of our knowledge, although several previous studies have reported a relationship between lung cancer risk and the $M P O \mathrm{G}-463 \mathrm{~A}$ polymorphism, only one previous study investigated the association between the MPO G-463A polymorphism and prostate cancer (6-14). It has been suggested that the $-463 \mathrm{~A}$ allele has a protective effect against some cancer types due to a single base substitution $(-463 \mathrm{G}>\mathrm{A})$ in the promoter region of $M P O$, which reduces transcription activity (1-3). It should be noted that the conclusions of these studies remain controversial. To date, the role of the $M P O$ $\mathrm{G}-463 \mathrm{~A}$ polymorphism in lung and prostate cancer has not been studied in a Turkish population. 
The present study investigated the relationship between the myeloperoxidase G-463A polymorphism and lung and prostate cancer related to tobacco smoking in a Turkish population.

\section{Materials and methods}

Study population. To determine the relationship between the MPO G-463A polymorphism and lung cancer, 377 individuals (106 cases and 271 controls) were examined. Regarding prostate cancer, the number of studied individuals was 276 (114 cases and 151 controls). Lung and prostate cancer patients were admitted to the Cumhuriyet University Hospital (Central Anatolia, Sivas, Turkey) during 2001. They were newly diagnosed, histologically confirmed and previously untreated. The controls were selected at random from healthy individuals without any history of cancer. Prostate cancer patients and controls had elevated serum levels of prostate-specific antigen (PSA). The controls had serum levels of PSA $<4 \mathrm{ng} / \mathrm{ml}$. Both cases and controls were born in Turkey, and information concerning age, gender and smoking habits was collected using a standardized questionnaire by trained interviewers. Informed consent was obtained from the patients before the study, and the study was approved by the Local Ethics Committee on Human Research of Cumhuriyet University.

MPO G-463A genotyping. Genomic DNA of the studied populations was extracted from blood leukocytes using a standard phenol-chloroform method (15). MPO genotypes were determined using polymerase chain reaction (PCR)-based restriction fragment length polymorphism (RFLP) assay. PCR was carried out in a $25-\mathrm{ml}$ vol containing $200 \mathrm{mM}$ of each deoxynucleotide triphosphate (dATP, dCTP, dGTP and dTTP), $0.2 \mathrm{mM}$ of each primer (F: 5'-CGG TAT AGG CAC ACA ATG GTG AG-3' and R: 5'-CAA TGG TTC AAG CGA TTC TTC-3'), 100 ng template DNA, 1X reaction buffer [75 mM Tris-HCI (pH 8.8) at $25^{\circ} \mathrm{C}, 20 \mathrm{mM}\left(\mathrm{NH}_{4}\right)_{2} \mathrm{SO}_{4}, 0.01 \%$ Tween-20; MBI Fermentas], $1.5 \mathrm{mM} \mathrm{MgCl}_{2}$ and 2 units Taq polymerase (MBI Fermentas). The temperature profile for the 35-cycle amplification reaction using a thermal cycler (Techne, $\mathrm{UK}$ ) was as follows: initial denaturation at $94^{\circ} \mathrm{C}$ for $5 \mathrm{~min}$, denaturation at $94^{\circ} \mathrm{C}$ for $30 \mathrm{sec}$, annealing at $62^{\circ} \mathrm{C}$ for $30 \mathrm{sec}$ and extension at $72^{\circ} \mathrm{C}$ for $30 \mathrm{sec}$, and a final extension at $72^{\circ} \mathrm{C}$ for $5 \mathrm{~min}$. Following the PCR, $10 \mu \mathrm{l}$ of 350-bp PCR product was digested with $10 \mathrm{U}$ of $A c i$ restriction enzyme according to the manufacturer's instructions (MBI, Fermentas). The DNA fragments were separated on $3 \%$ agarose gel stained with ethidium bromide. The wild-type homozygous genotype $(G G)$ yielded three bands (169, 120 and $61 \mathrm{bp})$, the heterozygous genotype $(G A)$ yielded four bands $(289,169,120$ and $61 \mathrm{bp})$, and finally the mutant genotype $(A A)$ yielded two bands (289 and $61 \mathrm{bp}$ ). In order to confirm the MPO genotypes, several wild and variant homozygote genotypes were selected for detection using the ABI 310 DNA sequencing system (Applied Biosystems, Iontek).

Statistical analysis. SPSS (Statistical Package for Social Sciences) release 13.0.1 software was used to perform the statistical analyses. Hardy-Weinberg equilibrium, genotype frequencies and allele frequencies were tested using the Pearson $\chi^{2}$ test. The statistical significance of the differences between the MPO genotypes among the cases and controls was assessed using the $\chi^{2}$ test. Probability values $<0.05$ were regarded as statistically significant. Odds ratios (ORs) and 95\% confidence intervals (CIs) were calculated using both an unadjusted and adjusted logistic regression analysis, adjusting several confounding variables such as age, gender and smoking status.

\section{Results}

Demographic parameters such as the gender, age and smoking status of lung and prostate cancer cases and controls are shown in Table I. The mean age of the lung cancer cases and controls was 53.4 (range, 30-85) and 49.9 (range, 26-82) years, respectively. The mean age of the prostate cancer cases and controls was 65.2 (range, 42-88) and 61 (range, 41-82) years, respectively. Distribution of gender and smoking status between the lung cancer cases and the controls was statistically significant (gender, $\mathrm{p}<0.001$ and smoking status, $\mathrm{p}=0.001$ ). In terms of smoking status among the prostate cancer patients, no significant difference was observed between the cases and controls $(\mathrm{p}=0.96)$.

The $M P O \mathrm{G}-463 \mathrm{~A}$ allele and genotype distribution of the lung cancer cases, prostate cancer cases and controls is shown in Table II. Among the lung cancer cases and the controls, the frequencies of the $-463 \mathrm{~A}$ allele were 20.3 and $28.5 \%$, respectively; in prostate cancer cases and controls, this frequency was 22.3 and $17.2 \%$, respectively. Distribution of the allelic frequency was statistically significant between the lung cancer cases and the controls $(\mathrm{p}=0.02)$, but was not statistically significant between the prostate cancer cases and controls $(\mathrm{p}=0.30)$. In both the lung and prostate cancer cases, no significant difference was determined between the cases and control populations in terms of genotype distribution $(p=0.07, p=0.53$, respectively). Control populations of lung and prostate cancer were found to be in Hardy-Weinberg equilibrium ( $\mathrm{p}=0.87$ and $\mathrm{p}=0.41$, respectively). To determine the potential protective effect against lung cancer of the $-463 \mathrm{~A}$ allele, the G/A and A/A genotypes were combined. Comparison of the $G / G$ and $\mathrm{G} / \mathrm{A}+\mathrm{A} / \mathrm{A}$ genotypes between the lung cancer cases and the control groups showed a statistically significant relationship $(\mathrm{p}=0.032, \mathrm{OR}=0.60,95 \% \mathrm{Cl} 0.38-0.95)$ (Table III). The results indicated that the $-463 \mathrm{~A}$ allele provided a protective effect for $40 \%$ of lung cancer cases. Therefore, overall and in males, the AA genotype was determined to have a higher protective effect against lung cancer than the GA and the GA + AA genotype combination.

Additionally, the relationship between the $M P O \mathrm{G}-463 \mathrm{~A}$ genotypes and lung cancer was analyzed on the basis of gender and smoking status (Table III). No statistically significant difference was determined in females or males in terms of genotype distribution between the lung cancer cases and the controls (female, $\mathrm{p}=0.20$; male, $\mathrm{p}=0.34$ ). In the case of smokers, genotype distribution between the lung cancer cases and the controls was found to be statistically significant $(\mathrm{p}=0.028, \mathrm{OR}=0.51,95 \% \mathrm{Cl} 0.28-0.93)$, while this difference was found to be insignificant for non-smokers $(\mathrm{p}=0.90, \mathrm{OR}=$ $0.95,95 \% \mathrm{Cl} \mathrm{0.43-2.07).}$ 
Table I. Demographic parameters of the lung and prostate cancer cases and controls.

\begin{tabular}{|c|c|c|c|c|}
\hline & \multicolumn{2}{|c|}{ Lung cancer } & \multicolumn{2}{|c|}{ Prostate cancer } \\
\hline & Cases, n (\%) & Controls, n (\%) & Cases, n (\%) & Controls, n (\%) \\
\hline Sample size & 106 & 267 & 114 & 151 \\
\hline \multicolumn{5}{|l|}{ Gender } \\
\hline Male & $88(83.1)$ & $126(47.2)$ & $114(100)$ & $151(100)$ \\
\hline Female & $18(16.9)$ & $141(52.8)$ & - & - \\
\hline \multicolumn{5}{|l|}{ Age (years) } \\
\hline Range & $30-85$ & $26-82$ & $42-88$ & $41-82$ \\
\hline Mean & $53.4 \pm 12.0$ & $49.9 \pm 11.1$ & $65.2 \pm 13.2$ & $61 \pm 11.4$ \\
\hline \multicolumn{5}{|l|}{ Smoking status } \\
\hline Smoker & $74(68.8)$ & $135(50.5)$ & $60(52.6)$ & $79(52.3)$ \\
\hline Non-smoker & $32(31.2)$ & $132(49.5)$ & $54(47.4)$ & $72(47.7)$ \\
\hline PSA (ng/ml) & - & - & $33.6 \pm 9.6$ & $3.4 \pm 0.3$ \\
\hline
\end{tabular}

PSA, prostate-specific antigen.

Table II. Allele and genotype distribution of the lung and prostate cancer cases and controls.

\begin{tabular}{|c|c|c|c|c|c|c|}
\hline & \multicolumn{3}{|c|}{ Lung cancer } & \multicolumn{3}{|c|}{ Prostate cancer } \\
\hline & Cases, n (\%) & Controls, n (\%) & P-value & Cases, n (\%) & Controls, n (\%) & P-value \\
\hline \multicolumn{7}{|c|}{ Allele frequency } \\
\hline $\mathrm{G}$ allele & $169(79.7)$ & $382(71.5)$ & & $175(76.7)$ & $220(72.8)$ & \\
\hline A allele & $43(20.3)$ & $152(28.5)$ & 0.02 & $53(22.3)$ & $82(17.2)$ & 0.30 \\
\hline \multicolumn{7}{|c|}{ Genotype frequency } \\
\hline $\mathrm{G} / \mathrm{G}$ & $67(63.2)$ & $136(50.9)$ & & $67(58.8)$ & $82(54.3)$ & \\
\hline $\mathrm{G} / \mathrm{A}$ & $35(33.01)$ & $110(41.1)$ & & $41(36.0)$ & $56(37.0)$ & \\
\hline $\mathrm{A} / \mathrm{A}$ & $4(3.79)$ & $21(7.0)$ & 0.07 & $6(5.2)$ & $13(8.7)$ & 0.53 \\
\hline
\end{tabular}

Overall, no statistically significant difference was found between the prostate cancer cases and the controls upon comparison of the genotype combinations $(\mathrm{p}=0.46, \mathrm{OR}=0.83$, 95\% CI 0.51-1.36) (Table III). However, the AA genotype was noted to have a protective effect of close to $45 \%$ against prostate cancer $(\mathrm{OR}=0.56,95 \% \mathrm{Cl} 0.20-1.56)$. In the smoker and non-smoker populations, no significant relationship was determined in terms of genotype distribution between the prostate cancer and control populations $(\mathrm{p}=0.21, \mathrm{p}=0.91$, respectively). However, in smokers, the presence of the GA and GA + AA genotypes provided a greater protective effect than in nonsmokers (Table III). Overall, in the smokers and non-smokers, the AA genotype was found to have a higher protective effect than the GA and the GA + AA genotype combination for prostate cancer (Table III).

\section{Discussion}

Genetic polymorphisms in xenobiotic metabolizing enzymes, such as the CYP450 family, N-acetyltransferases (NAT), glutathione-s-transferases (GST) and sulfotransferases, have been thought to play an important role in the susceptibility of individuals to cancer (16). The MPO gene contains a common single nucleotide polymorphism (SNP) within the $M P O-463$ gene promoter. Allelic frequencies of variant $M P O-463 \mathrm{~A}$ differ widely among ethnic populations. In the present study, the frequency of the $-463 \mathrm{~A}$ allele in the lung cancer controls $(n=271)$ was $28.5 \%$. The frequency of the A allele was previously found to be $20.9 \%$ in Caucasians $(n=1128), 26.7 \%$ in French-Canadians $(n=217), 25 \%$ in Italians $(n=214), 29.9 \%$ in African-Americans and $21.2 \%$ in Chinese populations $(n=139)$ $(6,10,17-21)$.

Since the MPO G-463A polymorphism was first reported by Austin et al in 1993, many subsequent studies have reported the relationship between different cancer types and this polymorphism (22). Many (but not all) of these studies reported a statistically significant relationship between the $M P O$ G-463A polymorphism and different cancer types, including lung cancer (6-14,17-19,21). According to the present study, possession of the GA + AA genotype has a statistically 
Table III. Risk estimates for MPO genotypes categorized by gender, smoking status and age.

\begin{tabular}{|c|c|c|c|c|c|c|c|}
\hline Variables & $\begin{array}{c}\text { Genotype } \\
\text { combinations }\end{array}$ & $\begin{array}{c}\text { Cases } \\
\mathrm{n}\end{array}$ & $\begin{array}{c}\text { Controls } \\
\mathrm{n}\end{array}$ & $\chi^{2}$ & P-value & $\begin{array}{l}\text { Unadjusted OR } \\
\quad(95 \% \mathrm{CI})\end{array}$ & $\begin{array}{l}\text { Adjusted OR } \\
(95 \% \mathrm{CI})\end{array}$ \\
\hline \multicolumn{8}{|l|}{ Lung cancer } \\
\hline \multirow[t]{4}{*}{ Overall } & GG & 67 & 136 & & & 1.00 (reference) & 1.00 (reference) \\
\hline & GA & 35 & 110 & 3.21 & 0.073 & $0.64(0.40-1.04)$ & $0.62(0.39-1.01)$ \\
\hline & $\mathrm{AA}$ & 4 & 21 & 3.00 & 0.083 & $0.38(0.12-1.17)$ & $0.41(0.14-1.21)$ \\
\hline & $\mathrm{GA}+\mathrm{AA}$ & 39 & 131 & 4.60 & 0.032 & $0.60(0.38-0.95)$ & $0.61(0.39-0.97)$ \\
\hline \multicolumn{8}{|l|}{ Gender } \\
\hline \multirow[t]{4}{*}{ Females } & GG & 11 & 64 & & & 1.00 & 1.00 \\
\hline & GA & 7 & 65 & 0.83 & 0.36 & $0.62(0.22-1.71)$ & $0.60(0.20-1.51)$ \\
\hline & AA & - & 12 & - & - & - & - \\
\hline & $\mathrm{GA}+\mathrm{AA}$ & 7 & 77 & 1.58 & 0.20 & $0.52(0.19-1.44)$ & $0.54(0.21-1.53)$ \\
\hline \multirow[t]{4}{*}{ Males } & GG & 56 & 72 & & & 1.00 & 1.00 \\
\hline & GA & 28 & 45 & 0.55 & 0.45 & $0.80(0.44-1.43)$ & $0.78(0.41-1.38)$ \\
\hline & AA & 4 & 9 & 0.81 & 0.36 & $0.57(0.16-1.95)$ & $0.55(0.13-1.85)$ \\
\hline & $\mathrm{GA}+\mathrm{AA}$ & 32 & 54 & 0.90 & 0.34 & $0.76(0.43-1.33)$ & $0.75(0.42-1.30)$ \\
\hline \multicolumn{8}{|l|}{ Smoking status } \\
\hline \multirow[t]{4}{*}{ Smokers } & GG & 50 & 70 & & & 1.00 & 1.00 \\
\hline & GA & 20 & 53 & 3.99 & 0.04 & $0.52(0.28-0.99)$ & $0.50(0.27-0.98)$ \\
\hline & $\mathrm{AA}$ & 4 & 12 & 1.63 & 0.20 & $0.46(0.14-1.53)$ & $0.45(0.12-1.48)$ \\
\hline & $\mathrm{GA}+\mathrm{AA}$ & 24 & 65 & 4.82 & 0.028 & $0.51(0.28-0.93)$ & $0.49(0.26-0.90)$ \\
\hline \multirow[t]{4}{*}{ Non-smokers } & GG & 17 & 66 & & & 1.00 & 1.00 \\
\hline & GA & 15 & 57 & 0.95 & 0.95 & $1.02(0.46-2.22)$ & $0.98(0.33-1.95)$ \\
\hline & AA & - & 4 & - & - & - & - \\
\hline & $\mathrm{GA}+\mathrm{AA}$ & 15 & 61 & 0.14 & 0.90 & $0.95(0.43-2.07)$ & $0.93(0.38-1.90)$ \\
\hline
\end{tabular}

\begin{tabular}{llrrllll}
\hline $\begin{array}{l}\text { Prostate cancer } \\
\text { Overall }\end{array}$ & GG & 67 & 82 & & & 1.00 & \\
& GA & 41 & 56 & 0.17 & 0.67 & $0.89(0.53-1.50)$ & $0.85(0.48-1.45)$ \\
& AA & 6 & 13 & 1.22 & 0.26 & $0.56(0.20-1.56)$ & $0.55(0.18-1.53)$ \\
& GA + AA & 47 & 69 & 0.52 & 0.46 & $0.83(0.51-1.36)$ & $0.79(0.49-1.33)$ \\
Smoking status & & & & & & & \\
Smokers & GG & 38 & 51 & & & 1.00 & 1.00 \\
& GA & 18 & 34 & 0.89 & 0.34 & $0.71(0.35-1.44)$ & $0.68(0.31-1.39)$ \\
& GA & 4 & 9 & 0.66 & 0.41 & $0.59(0.17-2.08)$ & $0.57(0.13-1.95)$ \\
Non-smokers & GA + AA & 22 & 45 & 1.57 & 0.21 & $0.65(0.33-1.27)$ & $0.62(0.29-1.19)$ \\
& GG & 29 & 29 & & & 1.00 & 1.00 \\
& GA & 23 & 22 & 0.01 & 0.91 & $1.04(0.48-2.27)$ & $1.01(0.39-2.11)$ \\
& AA & 2 & 4 & 0.06 & 0.43 & $0.50(0.85-2.94)$ & $0.51(0.82-2.83)$ \\
& GA + AA & 25 & 24 & 0.01 & 0.91 & $1.04(0.48-2.22)$ & $1.02(0.46-2.12)$ \\
\hline
\end{tabular}

significant protective effect against lung cancer $(\mathrm{p}=0.02)$. In addition, overall it was determined that the AA genotype had a greater protective effect than either the GA or the GA + AA genotype combination against lung cancer. This finding is in agreement with many previous studies (7-13). London et al were the first to report an association between a variant allele of $M P O$ and the risk of lung cancer (11). In addition, a study by Schabath et al of 903 lung cancer patients reported that the $-463 \mathrm{~A}$ allele had a statistically significant protective effect (12). A meta-analysis showed that Caucasians carrying the $-463 \mathrm{~A}$ allele have an approximately $20-30 \%$ reduced risk for lung cancer (6). MPO is a phase I metabolic enzyme that has a polymorphic region upstream of the gene that appears to reduce transcriptional activity (3-5). Thus, individuals with the variant allele may be provided with a protective effect due to decreased metabolic bioactivation of carcinogenic compounds. This hypothesis is supported by the findings of the present study and many previous reports $(3,23)$.

In the present study, the $-463 \mathrm{~A}$ allele was shown to have a statistically significant protective effect in smokers. A comprehensive study (3688 cases and 3874 controls) concluded that the myeloperoxidase G-463A polymorphism was significantly 
protective in smokers, but not in non-smokers (23). It was also concluded that MPO converts tobacco smoke procarcinogens, such as benzo $(\alpha)$ pyrene and arylamines, into highly carcinogenic intermediates, such as benzo $(\alpha)$ pyrene dio-epoxide $(1,3)$. Since the variant allele may be associated with weaker transcriptional activity, carcinogens contained in cigarette smoke will not be metabolically activated, therefore the $-463 \mathrm{~A}$ allele has been suggested to have a protective effect against the development of cancer related to smoking. The present study and a significant proportion of previous reports found similar results with regard to the MPO polymorphism and lung cancer related to tobacco smoking $(6,8,15,23)$.

In the present study, no significant relationship was found in terms of the MPO genotype between lung cancer cases and controls, in either the male or female populations. However, the GG + GA genotype was found to have a $46 \%$ protective effect against lung cancer in females, and a $25 \%$ protective effect in males. Therefore, a $46 \%$ protective effect was found between the lung cancer cases and the controls for males with the AA genotype. Taioli et al conducted a meta-analysis of 10 studies and reported that an inverse association between lung cancer and the $M P O \mathrm{G}-463 \mathrm{~A}$ polymorphism was found equally in males and females, with no differences in the association according to age in the two genders (23).

No statistically significant difference was found between the prostate cancer cases and the controls in terms of the $M P O$ G-463A genotype. A review of the literature identified only one previous study indicating a relationship between the $M P O$ G-463A polymorphism and prostate cancer (14). That study used 661 prostate cancer patients and 1310 control individuals, and found no statistically significant difference between the $M P O \mathrm{G}-463 \mathrm{~A}$ polymorphism and prostate cancer. On the other hand, a $40 \%$ protective effect against prostate cancer was detected in males having the MPO AA genotype. In the present study, the risk of prostate cancer was found to be $45 \%$ lower among males with the MPO AA genotype. This finding is in close agreement with the findings of Choi et al (14). In addition, the present study found no statistically significant relationship in terms of genotype combinations between the prostate cancer patients and controls in either the smokers and non-smokers. On the other hand, smokers with the AA and AA + GA genotypes were found to have 43 and $38 \%$ protective effects, respectively, between the prostate cancer patients and controls. Our findings, suggesting a decreased risk of prostate cancer for males with the MPO AA genotype, which is associated with lower transcription and subsequent decreased metabolic activation of procarcinogens, are consistent with some (but not all) previous findings for several types of cancer including prostate cancer $(17-19,21,23)$.

In conclusion, the relationship between the MPO G-463A polymorphism and lung and prostate cancer was evaluated in a Turkish population for the first time. In the cases overall and in smokers, the $-463 \mathrm{~A}$ allele was found to have a statistically significant protective effect against lung cancer. While no statistically significant relationship was found for prostate cancer, the AA genotype was shown to have a protective effect in these individuals. Further extensive studies are required, particularly regarding prostate cancer, in order to better clarify the role of the MPO genotype in mediating susceptibility to lung and prostate cancer.

\section{References}

1. Klebanoff SJ: Myeloperoxidase: occurrence and biological function. In: Peroxidases in Chemistry and Biology. Everse J, Everse KE and Grisham MB (eds). CRC Press, Boca Raton, pp1-35, 1997

2. Piedrafita FJ, Molander RB, Vansant G, Orlova EA, Pfahl M and Reynolds WF: An Alu element in the myeloperoxidase promoter contains a composite SP1-thyroid hormone-retinoic acid response element. J Biol Chem 271: 14412-14420, 1996.

3. Van Schooten FJ, Boots AW, Knaapen AM, Godschalk RW, Maas LM, Borm PJ, Drent M and Jacobs JA: Myeloperoxidase (MPO) $-463 \mathrm{G} \rightarrow \mathrm{A}$ reduces MPO activity and DNA adduct levels in bronchoalveolar lavages of smokers. Cancer Epidemiol Biomark Prev 13: 828-833, 2004.

4. Jemal A, Siegel R, Xu J and Ward E: Cancer statistics 2010. CA Cancer J Clin 60: 277-300, 2010.

5. Perera FP: Molecular epidemiology: insights into cancer susceptibility, risk assessment, and prevention. J Natl Cancer Inst 88: 496-509, 1996.

6. Xu LL, Liu G, Miller DP, Zhou W, Lynch TJ, Wain JC, Su L and Christiani DC: The myeloperoxidase $-463 \mathrm{G} \rightarrow \mathrm{A}$ polymorphism does not decrease lung cancer susceptibility in Caucasians. Cancer Epidemiol Biomark Prev 11: 1555-1559, 2002.

7. Feyler A, Voho A, Bouchardy C, Kuokkanen K, Dayer P, Hirvonen A and Benhamou S: Myeloperoxidase $-463 \mathrm{G} \rightarrow \mathrm{A}$ polymorphism and lung cancer risk. Cancer Epidemiol Biomarkers Prev 11: 1550-1554, 2002.

8. Dally H, Gassner K, Jäger B, Schmezer P, Spiegelhalder B, Edler L, Drings P, Dienemann H, Schulz V, Kayser K, Bartsch H and Risch A: Myeloperoxidase (MPO) genotype and lung cancer histologic types: the MPO -463 A allele is associated with reduced risk for small cell lung cancer in smokers. Int J Cancer 102: 530-535, 2002

9. Kiyohara C, Yoshimasu K, Takayama K and Nakanishi Y: NQQ1, MPO, and the risk of lung cancer: a huge review. Genet Med 7: 463-478, 2005.

10. LuW, Xing D, Qi J, TanW, Miao X and Lin D: Genetic polymorphism in myeloperoxidase but not GSTM1 is associated with risk of lung squamous cell carcinoma in a Chinese population. Int J Cancer 102: 275-279, 2002.

11. London, SJ, Lehman TA and Taylor JA: Myeloperoxidase genetic polymorphism and lung cancer risk. Cancer Res 57: 5001-5003, 1997.

12. Schabath MB, Spitz MR, Zhang X, Delclos GL and Wu X: Genetic variants of myeloperoxidase and lung cancer risk. Carcinogenesis 21: 1163-1166, 2000.

13. Park JH, Park JM, Kim EJ, Cha SI, Lee EB, Kim CH, Kam S, Jung TH and Park JY: Myeloperoxidase -463G $>$ A polymorphism and risk of primary lung cancer in a Korean population. Cancer Detect Prev 30: 257-261, 2006.

14. Choi JY, Neuhouser ML, Barnett MJ, Hong CC, Kristal AR, Thornquist MD, King IB, Goodman GE and Ambrosone CB: Iron intake, oxidative stress-related genes (MnSOD and MPO) and prostate cancer risk in CARET cohort. Carcinogenesis 29: 964-970. 2008.

15. Sambrook J, Fritsch E and Maniatis T: Molecular Cloning - A Laboratory Manual. 2nd edition. Cold Spring Harbor Laboratory Press, Cold Spring Harbor, NY, 1989.

16. Wormhoudt LW, Commandeur JNM and Vermeulen NP: Genetic polymorphisms of human N-acetyltransferase, cytochrome P450, glutathione-S-transferase, and epoxide hydrolase enzymes: relevance to xenobiotic metabolism and toxicity. Crit Rev Toxicol 29: 59-124, 1999.

17. Olson SH, Carlson MD, Ostrer H, Harlap S, Stone A, Winters M and Ambrosone CB: Genetic variants in SOD2, MPO, and NQO1, and risk of ovarian cancer. Gynecol Oncol 93: 615-620, 2004.

18. Ahn J, Gammo n MD, Santella RM, Gaudet MM, Britton JA, Teitelbaum SL, Terry MB, Neugut AI, Josephy PD and Ambrosone CB: Myeloperoxidase genotype, fruit and vegetable consumption, and breast cancer risk. Cancer Res 64: 7634-7639, 2004.

19. Matsuo K, Hamajima N, Shinoda M, Hatooka S, Inoue M, Takezaki T, Onda $\mathrm{H}$ and Tajima $\mathrm{K}$ : Possible risk reduction in esophageal cancer associated with MPO -463 A allele. J Epidemiol 11: 109-114, 2001.

20. Nikpoor B, Turecki G, Fournier C, Théroux P and Rouleau GA: A functional myeloperoxidase polymorphic variant is associated with coronary artery disease in French-Canadians. Am Heart J 142: 336-339, 2001. 
21. Hung RJ, Boffetta $P$, Brennan $P$, Malaveille C, Gelatti U, Placidi D, Carta A, Hautefeuille A and Porru S: Genetic polymorphisms of MPO, COMT, MnSOD, NQO1, interactions with environmental exposures and bladder cancer risk. Carcinogenesis 25: 973-978, 2004

22. Austin GE, Lam L, Zaki SR, Chan WC, Hodge T, Hou J, Swan D, Zhang W, Racine M, Whitsett C and Brown B: Sequence comparison of putative regulatory DNA of the 5' flanking region of the myeloperoxidase gene in normal and leukemic bone marrow cells. Leukemia 7: 1445-1450, 1993.
23. Taioli E, Benhamou S, Bouchardy C, Cascorbi I, Cajas-Salazar N, Dally H, Fong KM, Larsen JE, Le Marchand L, London SJ, Risch A, Spitz MR, Stucker I, Weinshenker B, Wu X and Yang P: Myeloperoxidase G-463A polymorphism and lung cancer: a HuGE genetic susceptibility to environmental carcinogen pooled analysis. Genet Med 9: 67-73 2007. 